\title{
The Effects \\ of Magnetic Fields \\ on Magnetic Storage Media Used in Computers
}

U.S. ARTMENT OF DMMERCE National bau PC of po rds 753 735 72 


\section{NATIONAL BUREAU OF STANDARDS}

The National Bureau of Standards ${ }^{1}$ was established by an act of Congress March 3 , 1901. The Bureau's overall goal is to strengthen and advance the Nation's science and technology and facilitate their effective application for public benefit. To this end, the Bureau conducts research and provides: (1) a basis for the Nation's physical measurement system, (2) scientific and technological services for industry and government, (3) a technical basis for equity in trade, and (4) technical services to promote public safety. The Bureau consists of the Institute for Basic Standards, the Institute for Materials Research, the Institute for Applied Technology, the Center for Computer Sciences and Technology, and the Office for Information Programs.

THE INSTITUTE FOR BASIC STANDARDS provides the central basis within the United States of a complete and consistent system of physical measurement; coordinates that system with measurement systems of other nations; and furnishes essential services leading to accurate and uniform physical measurements throughout the Nation's scientific community, industry, and commerce. The Institute consists of a Center for Radiation Research, an Office of Measurement Services and the following divisions:

Applied Mathematics-Electricity-Heat-Mechanics-Optical Physics-Linac Radiation ${ }^{2}$ - Nuclear Radiation ${ }^{2}$ - Applied Radiation ${ }^{2}$ - Quantum Electronics ${ }^{3}$ Electromagnetics ${ }^{3}$-Time and Frequency ${ }^{3}$ - Laboratory Astrophysics ${ }^{3}-$ Cryo- $^{2}$ genics ${ }^{2}$.

THE INSTITUTE FOR MATERIALS RESEARCH conducts materials research leading to improved methods of measurement, standards, and data on the properties of well-characterized materials needed by industry, commerce, educational institutions, and Government; provides advisory and research services to other Government agencies; and develops, produces, and distributes standard reference materials. The Institute consists of the Office of Standard Reference Materials and the following divisions:

Analytical Chemistry-Polymers-Metallurgy-Inorganic Materials-Reactor Radiation-Physical Chemistry.

THE INSTITUTE FOR APPLIED TECHNOLOGY provides technical services to promote the use of available technology and to facilitate technological innovation in industry and Government; cooperates with public and private organizations leading to the development of technological standards (including mandatory safety standards), codes and methods of test; and provides technical advice and services to Government agencies upon request. The Institute also monifors NBS engineering standards activities and provides liaison between NBS and national and international engineering standards bodies. The Institute consists of the following divisions and offices:

Engineering Standards Services-Weights and Measures-Invention and Innovation-Product Evaluation Technology-Building Research-Electronic Technology-Technical Analysis-Measurement Engineering-Office of Fire Programs.

THE CENTER FOR COMPUTER SCIENCES AND TECHNOLOGY conducts research and provides technical services designed to aid Government agencies in improving cost effectiveness in the conduct of their programs through the selection, acquisition, and effective utilization of automatic data processing equipment; and serves as the principal focus within the executive branch for the development of Federal standards for automatic data processing equipment, techniques, and computer languages. The Center consists of the following offices and divisions:

Information Processing Standards-Computer Information-Computer Services -Systems Development-Information Processing Technology.

THE OFFICE FOR INFORMATION PROGRAMS promotes optimum dissemination and accessibility of scientific information generated within NBS and other agencies of the Federal Government; promotes the development of the National Standard Reference Data System and a system of information analysis centers dealing with the broader aspects of the National Measurement System; provides appropriate services to ensure that the NBS staff has optimum accessibility to the scientific information of the world, and directs the public information activities of the Bureau. The Office consists of the following organizational units:

Office of Standard Reference Data-Office of Technical Information and Publications-Library-Office of International Relations.

\footnotetext{
1 Headquarters and Laboratories at Gaithersburg, Maryland, unless otherwise noted; mailing address Washington, D.C. 20234

2 Part of the Center for Radiation Research.

3 Located at Boulder, Colorado 80302.
} 


\section{The Effects of Magnetic Fields on}

\section{Magnetic Storage Media Used in Computers}

Sidney B. Geller

Information Processing Technology Division

Center for Computer Sciences and Technology

National Bureau of Standards

Washington, D.C. 20234

techniral note no nos

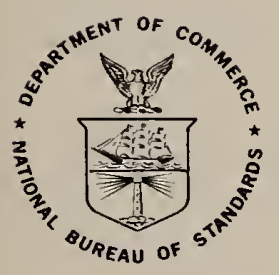

U.S. DEPARTMENT OF COMMERCE, Peter G. Peterson, Secrełary NATIONAL BUREAU OF STANDARDS, Lawrence M. Kushner, Acting Director, Issued July 1972 
National Bureau of Standards Technical Note 735

Nat. Bur. Stand. (U.S.), Tech. Note 735,35 pages (July 1972)

CODEN: NBTNAE

For sale by the Superintendent of Documents, U.S. Government Printing Office, Washington, D.C. 20402 (Order by SD Catalog No. C13.46:735). Price 40 cents. 
1. Introduction. . . . . . . . . . . . . . . . . 1

2. General Guidelines for Protection Against Damage to Magnetic Recording Media. . . . . . . . . . . . 2

3. Effects of Magnetic Fields on Recorded Media. . . . . . 3

3.1 Answers to Specific Questions of Interest to Computer Installation Managers . . . . . . . . 3

4. Description of Experiments. . . . . . . . . . . 12

4.1 Experimental Procedures. . . . . . . . . . 12

4.2 Smal1 Bar Magnet Experiments . . . . . . . . 15

4.3 Large Magnet Experiments and Tests . . . . . . . 16

5. Additional Test Results and Comments. . . . . . . . 25

6. References. . . . . . . . . . . . . . . 29

List of Figures

1. Variations in Pulling Force for Magnets of Different Weights . . . . . . . . . . . . . . . . .

2. Effect of a Single Bar Magnet on a Recorded Computer Tape....................... . . 13

3. Effect of 2 Bar Magnets on a Recorded Computer Tape . . 14

4. Magnetic Field Produced by the Large Test Magnet. . . . . 17

5. Effect of a Large Magnet in Contact with the Recorded Tape Ree1 (Test 1 Chart). . . . . . . . . . . 18

6. Measured and Calculated Percentage Decreases in Recorded Signal Levels . . . . . . . . . . . . . . 19

7. Effect of a Large Magnet $25.4 \mathrm{~mm}$ (1 in) from Recorded Tape Reel (Test ? Chart). . . . . . . . . . . . $? 0$

8. Effect of Mu-metal Shield (Test 3 Chart). . . . . . . 21

9. Effect of a Large Magnet in Contact with Plastic Tape Case (Test 5 Chart) . . . . . . . . . . . . .

10. Effect of a Large Magnet in Contact with the Recorded Tape Reel (Test 6 Chart: 200 frpi) . . . . . . . . 24

11. Effects of Temperature and Humidity on Magnetic Tapes . 


\section{FOREWORD}

The NBS Center for Computer Sciences and Technology undertakes research and advisory services aimed at improving the efficiency of data processing operations in industry and Government. In recent years there has been concern for the protection against unwarranted erasure of important computer records that are maintained and stored on magnetic media. This study has been initiated by Dr. Ruth M. Davis in response to the questions that were raised by the office of Management and Budget in Section 3. The report investigates the effects on recorded media of magnetic fields that are produced by sources such as permanent magnets. Guidelines for protecting magnetic tape, disk and drum files by installation managers are suggested by Dr. Davis in Section 2.

This study was supported by the National Bureau of Standards Magnetic Media Program*.

*Through Research and Technical Service Project 6501111 
The Effects of Magnetic Fields on Magnetic

Storage Media Used in Computers

\section{Sidney B. Geller}

Experiments have been performed with different types of magnets to determine their effects on the information stored on magnetic storage media. The test results that were obtained with recorded computer tapes are discussed and guidelines are suggested to computer installation managers for protecting their recorded tapes, disks and drums against unwarranted erasure by magnetic fields. The effects of other forms of energy on recorded magnetic media are briefly considered.

Key words: erasure, magnetic media; erasure, permanent magnet; erasure, shielding against; erasure, signal

loss due to; magnet fields, erasure with; magnetic media, computer; magnetic media, information damage; permanent magnets; permanent magnet, erasure with; shielding.

\section{INTRODUCTION}

Magnetic storage media have become indispensible to data processing operations in industry and in government. Magnetic tapes, disks and drums are used to store voluminous quantities of data on both a temporary and an archival basis. Unfortunately, data in magnetic form can be altered or destroyed by devices that are able to exert magnetic forces on the surfaces of these media. Such destructive action can be either intentional or unintentional. The most effective and insidious of the destructive devices is the simple permanent magnet which can produce powerful erasing fields and is easily obtained, carried and concealed. In addition, it requires no external power sources for producing or maintaining its fields.

This first report deals primarily with the effects of permanent magnets on the recorded information on magnetic computer tapes. The results of this study are directly applicable to the other magnetic surface devices such as disks and drums. The study also discusses both the capabilities and limitations of the permanent magnet and the electromagnet as destructive devices.

Section 2 of this report presents a number of guidelines to be used in computer installations for protecting their magnetically recorded data from intentional or accidental damage.

Section 3 uses a question-and-answer format to discuss topics that are of interest to the managers of computer installations. These deal mainly with the effects of magnetic fields on recorded magnetic computer tapes. 
Section 4 describes the experiments that were performed in order to answer some of the questions that were posed in Section 3.

Section 5 presents additional test results and comments concerning the effects of other possible sources of damage to magnetic media.

\section{GENERAL GUIDELINES FOR PROTECTION AGAINST DAMAGE TO MAGNETIC RECORDING MEDIA}

The results of both experience and of the tests that will be discussed in Sections 3 and 4 provide support for the following rules-of-thumb for protecting computer installations aginst damage to their magnetic recording media and the stored magnetic data:

a. When not in use, magnetic tapes (reel or cassette) and disk packs should be stored in storage cabinets with adequate shielding qualities. If the tape reels, tape cassettes and disk packs are stored one foot from the inner walls of the cabinet, no degradation of recorded signals will be caused by magnets or electromagnetic devices which are carried into the storage room or are capable of being used outside of the storage area. Several manufacturers* produce both suitable cabinets and shielding material and will supply quantitative data on their shielding qualities. Additional protection is afforded the magnetic media by the normal ferromagnetic metal walls found in many computer installations. These reduce the effects of magnets applied from outside the computer room by two-to-three orders of magnitude. Any metal wall to which a magnet will adhere will provide some shielding against magnetic fields. At the present time the drum and disk cabinets are normally made of plastic; however, they could also be made from shielding materials that will provide the same protection as the previously mentioned storage units.

b. A tape vault should be installed as far away as possible from all fixed sources of stray magnetic fields such as large transformers, motors and generators. When necessary, individually shielded containers are available for tape reels that contain important data. Shielded containers are particularly valuable for transporting these reels. The tapes in repository should not be subjected to temperature extremes, since these are capable of producing both physical damage as well as signal erasure effects. (See figure 11).

c. Since a magnet with a field intensity of 1 tes la $(10,000$ gauss) can be carried in a briefcase or a ladies handbag it is recommended that measures should be undertaken to prevent the entry of persons possessing such devices. Magnetic detectors (e.g., magnetometers) may be used at close range to apprehend these individuals. Detectors which will warn of concealed magnets without

*For example, see the "eem" Catalog, United Technical Publications, Vol. 3, p. 2018 and p. 2088 (1971-72). 
"keepers" are quite inexpensive (less than \$1000). Detectors which will protect against magnets with keepers will probably cost from $\$ 1000$ to $\$ 5000$ and are effective against magnets with 0.002 to 0.01 tesla (20-100 gauss) field intensities.

d. It is difficult to retrieve recorded information from a magnetic medium whose timing or clock track signals have been intentionally damaged. This damage can be done with magnetic devices or by interfering with the recorded process as it actually occurs. Devices such as simple spark gap units plugged into wall outlets or smal1 concealed battery operated transmitters can cause interference with the magnetic recording process as well as with other computer functions. Therefore, regular searches of the entire facility should be conducted for such devices and only authorized persons should be permitted to enter the computer installation.

e. Duplicate copies of al1 important tapes such as master tapes and program tapes should be made and kept in a different secure location.

\section{EFFECTS OF MAGNETIC FIELDS ON RECORDED MEDIA}

3.1 Answers to Specific Questions of Interest to Computer Insta1lation Managers

Several (i.e., eight) questions have been asked indicative of those that confront computer installation managers faced with guarding against intentional (or unintentional) attempts to use magnetic devices to destroy information recorded on magnetic media. These questions along with their answers are presented in subsequent paragraphs.

\section{a. Question 1}

Is there an easily understandable relationship between such factors as magnet size or power, distance, and time? How do these relate to the process of information destruction on magnetic media?

(1) We can interpret magnet "power" as the ability of a magnet to exert a force on any object or material that is capable of reacting to its magnetic field. The most sensitive of these materials are "ferromagnetic" materials such as iron or the oxides of iron that are found in the coating of magnetic tapes. These materials can be made to move physically under the influence of the magnetic field or in the case of a magnetic tape the microscopic "domains" in the iron oxide can be affected by the field in such a way as to produce the magnetized "patterns" in the coating that represent the desired signals on the tape. Of course, it is possible that the magnetic field is an undesirable one and, therefore, it alters or destroys the existing tape signal patterns. 
(2) NOTE: This report wi11 use the new International System of Units known as "SI" units. In each case the SI unit will be followed by the "customary" units in parentheses. The conversion factors are given in the appendix.

(a) The strength or intensity of a magnetic field is described in units of "amperes per meter" (oersteds).

(b) The density of the magnetic "flux lines" in the magnetic field which is also indicative of the strength of the field is measured in units of "teslas" (gauss). The gauss and the oersted are usua $11 \mathrm{y}$ considered to be equal to each other in value when the field is measured in air.

(c) The following symbols for SI units will be used:

$\begin{array}{ll}\text { amperes per meter } & =\mathrm{A} / \mathrm{m} \\ \text { kilograms } & =\mathrm{kg} \\ \text { meters } & =\mathrm{m} \\ \text { millimeters } & =\mathrm{mm} \\ \text { newtons } & =\mathrm{N} \\ \text { teslas } & =\mathrm{T}\end{array}$

(3) The relationship of the greatest interest for protecting tape files is that between the magnet and its distance from the object upon which it is exerting its force. Genera11y, magnetic forces produced by magnets are appreciable only over very short distances. The field strength of the magnet decreases very rapidly with distance from the magnet. For example, one permanent " $U$ " shaped magnet showed a measured field strength of approximately $56,000 \mathrm{~A} / \mathrm{m}$ (700 oersteds) on a line between its pole faces. At $51 \mathrm{~mm}$ (2 inches) from the magnet the field strength dropped to $6800 \mathrm{~A} / \mathrm{m}$ (85 oersteds) and at $76 \mathrm{~mm}$ (3 inches) it dropped to $2600 \mathrm{~A} / \mathrm{m}$ (33 oersteds).

A rule-of-thumb that relates the field strength of a magnet to the distance from the magnet is that the field strength decays at the rate of approximately

$$
\frac{1}{\text { distance }} \times \frac{1}{\text { distance }} \times \frac{1}{\text { distance }}=\frac{1}{(\text { distance })^{3}}
$$

It must be stressed that a great a11y of the computer insta1lation manager is the distance between the tape library and the unwanted magnetic field. A barrier against unauthorized personnel just a few feet from the tape vault will be extremely effective in preventing damage from magnetic fields.

A field that is produced by a permanent magnet and the field that is produced by an electromagnet powered by batteries have the same erasure effects. However, an electromagnet develops its magnetic field only when it is energized by the batteries and is used 
in applications in which it is necessary to vary the strength of the field. For example, in conveying scrap iron it is necessary to release as wel1 as to lift the metal; therefore, the magnetic field strength must be variable.

The ability of a magnetic material to resist the erasure of its recorded information is mostly dependent upon a quality known as "coercivity" which is measured in units of amperes per meter (oersteds). The higher the coercivity of a material the more difficult it is either to record onto or to erase information from its magnetic surface. In order to erase the recorded signal completely it is necessary that the strength of the erasing field is greater in value than the coercivity of the medium. For example, the coercivities of typica 1 magnetic computer tape range in value from approximately 20,000 to $21,000 \mathrm{~A} / \mathrm{m}$ (250 to 265 oersteds); therefore, any magnetic field whose peak strength is less than these values cannot erase the signal entirely from the tape. Commercial equipments that are used specifically for erasing the recorded data from the tapes will usually develop magnetic fields that are at least 5 times as great as the coercivity of the tape. In addition, these fields must extend through every area of the oxide surface in order to produce complete erasure. From these considerations it can be seen that once the previously described magnet has been moved to a distance of more than $51 \mathrm{~mm}$ (2 in) from the surface of the tape it is no longer able to significantly damage the tape record.

(4) The relationship between a magnetic field and the length of the time that it exerts its influence on the recorded medium is complex. However, it can be stated that if the magnetic field is strong enough to completely erase the tape data it will do its maximum damage almost instantaneously. Lesser field strengths produce erasure and second-order effects more gradually, but no matter how long a recorded tape remains in either a steady or a varying magnetic field it cannot be completely erased unless the peak or maximum value of the field is greater than the coercivity of the tape. The effect of a field is slightly different depending upon whether it is a slowly varying magnetic (ac) field or a steady value (dc) field. Slowly varying (ac) fields are produced by devices such as motors, generators and transformers, while steady fields are produced by permanent magnets and direct current electromagnets. The devices are normally designed with shields that tend to keep their ac magnetic fields from permeating the surrounding environment but some leakage may occur. The strength of a slowly varying (ac) magnetic field decreases inversely with distance cubed in the same way as the steady field from the permanent magnet.

There are some second-order effects that result from subjecting recorded tapes to relatively weak ac and dc magnetic fields. For example, a small steady field from a permanent magnet can cause a form of background "noise" to appear on a recorded tape that becomes greater in intensity as the tape remains in the field for longer periods of time. While this noise may be undesirable for audio tapes 
it is of no importance in a digital system. This noise effect is often caused on magnetic tapes by recording heads that have become magnetized and behave like ordinary, weak permanent magnets. This is why recording heads should be demagnetized by equipments specifically designed for this purpose that are known as "degaussers". Stray varying (ac) fields can also cause erasure of recorded data in proportion to the highest or "peak" strength that the field may attain. A relatively weak ac field can enhance "signal transfer" or "print-through" effects on a reel of magnetic tape. Print-through is the process by which the desired recorded signal on one layer of tape can cause an adjacent layer against which it is wound to develop a weak version of the same signal pattern. The longer the recorded tape is subjected to the external ac field, the stronger the "printthrough" signal becomes $[1]^{1}$. Print-through effects are worsened if the tapes are stored in higher temperature environments. Print-through, however, is not a significant factor in digital recordings. Another interesting time dependent effect is that the longer a recorded tape has been stored the harder it is to erase the signa 1. That is, it is easiest to remove the magnetic pattern from a tape immediately after it has been recorded. If the peak value of an external ac field is strong enough to damage the signal on a tape then the longer that tape is within the field the more effective the erasing action will be. A stronger ac field will be more effective in less time than a weaker ac field. A field strength of approximately $4000 \mathrm{~A} / \mathrm{m}$ (50 oersteds) will begin to affect the amplitude of a recorded digital signal. This level, however, will not damage the information content irretrievably.

(5) The metallurgical and physical design of a permanent magnet is a very complicated process. There is considerable interaction among the various parameters such as magnet length, cross-section area, shape, gap size, chemical composition, etc. As a general rule the field strength and "pulling force" of a permanent magnet increases when the volume (or weight) of the magnet increases for a given magnetic material and shape. Figure 1 shows the power or "pulling force" exerted by a group of magnets of the same " $U$ " shape but different weights*. The pulling force is measured in terms of the attraction of each magnet to a thick piece of iron. Note the rapid decrease in magnet power with distance from the iron piece. For example, the pulling force of the $18 \mathrm{~kg}$ ( $40 \mathrm{lbs}$ ) horse-shoe shaped magnet

decreased from approximately $2800 \mathrm{~N}$ (620 pounds force) to approximately $13 \mathrm{~N}$ ( 3 pounds force) within $76 \mathrm{~mm}$ (3 in).

\footnotetext{
${ }^{1}$ Figures in brackets indicate the literature references at the end of this paper.
}

*Alnico VB magnets; Crucible Steel Company of America. 


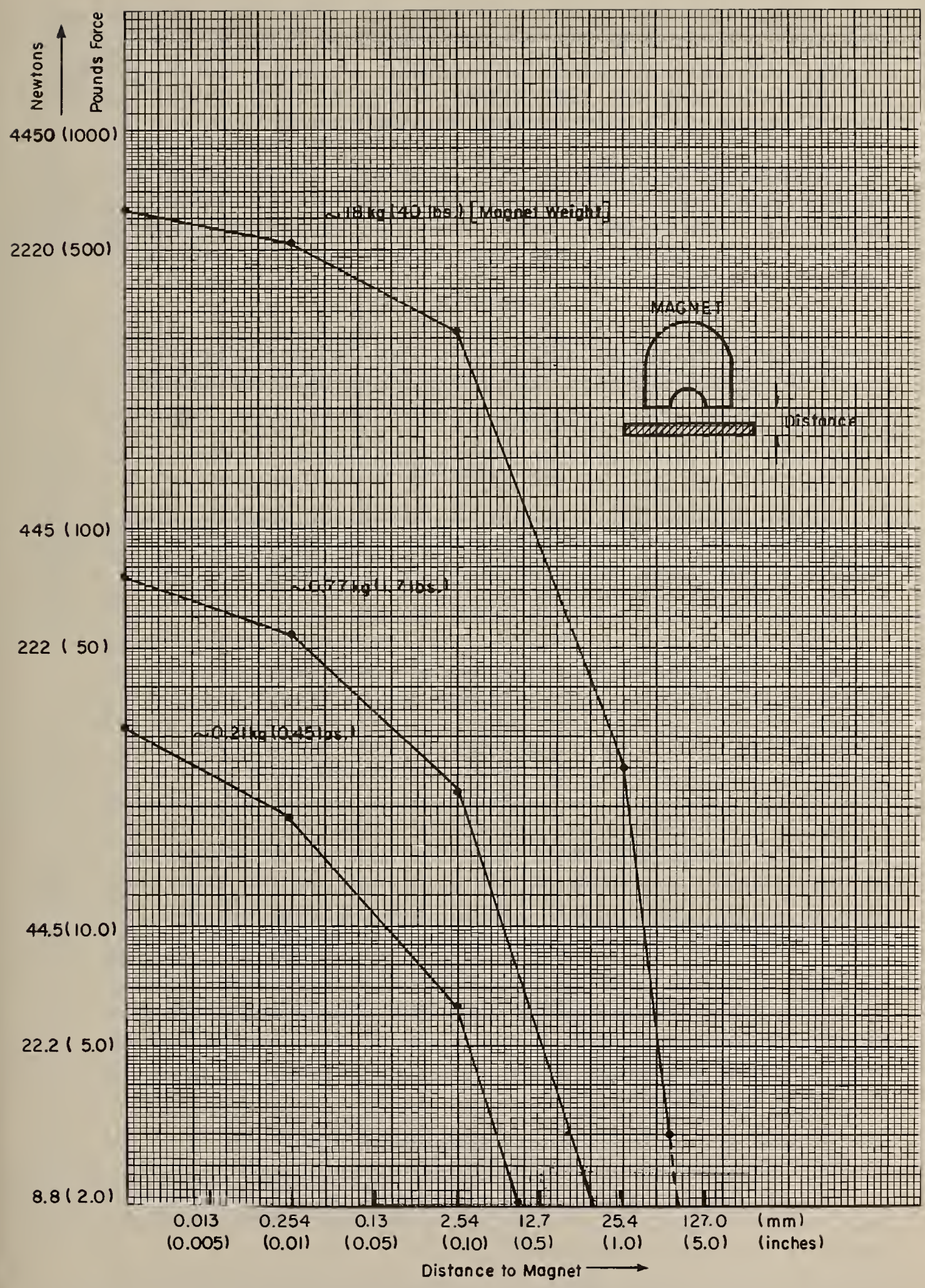

Figure 1. Variations in Pulling Force for Magnets of Different Weights. 
The shape of the magnet w111 affect its pulling power as we 11 as its ability to produce the greatest magnetic fleld at a distance. A long, straight bar magnet will produce a greater field strength at a distance than the same magnet bent into a " $U$ " shape. However, the "U" magnet will have greater pulling power.

Modern advances in magnetic materials have produced permanent magnets with fields that are extremely powerful in spite of their small size. For example, a new group of cobalt-rare earth materials such as cobalt-samarium have been discovered which have unusual magnetic properties [2].

Most of the experimental details from which the answers to the following questions were derived are given in section 4 . It should be understood that the answers also apply to magnetic disks and drums when they are subjected to the same conditions.

\section{b. Question 2}

Could someone put a couple of little bar magnets, such as we use to hang papers on steel walls in a plastic tape case, put the case on a tape rack, erase and destroy a significant number of reels on the rack over a period of months?

(1) The length of time that the magnets are near to the recorded tapes has no relationship to their effectiveness in obliterating the tape data. If the fields from the magnets are capable of erasing the tape they will do so as soon as the tape is in their vicinity. In a test these little bar magnets whose field strengths averaged from approximately 44,000 to $52,000 \mathrm{~A} / \mathrm{m}$ (550 to 650 oersteds) were contacted singly and in-pairs against the flange of a recorded reel of computer tape. Figure 3 in section 4.2 shows that they were able to cause as much as a $35 \%$ decrease in the recorded signal amplitude on the track next to the edge track when used in pairs. This can be significant for some systems. Question 2 as posed, however, indicates that these magnets are to be placed into an adjoining plastic tape case. This produces a considerable "spacing loss" for the magnetic fleld and, therefore, reduces its erasing effects by moving the tape into a much weaker part of the field. It was found that if the tapes as well as the magnets are both enclosed in plastic cases then the erasing effect is negligible for these bar magnets.

\section{c. Question 3}

Could someone put a $51 \mathrm{~mm} \times 102 \mathrm{~mm}$ ( 2 in $\times 4$ in) magnetic picture hook in his pocket, walk by a tape rack, and destroy a significant number of tapes in the rack?

(1) The maximum magnetic flux density close to the surface of each of a group of magnetic picture hooks was measured as 0.045 to $0.05 \mathrm{~T}$ (450 to 500 gauss). They had no effect at a 11 on the signal 
when carried in a pocket in the vicintty of a recorded reel of tape. One of these magnets was firmly pressed directly against the exposed flange of a reel of tape. The track next to the edge track experienced an $8 \%$ decrease in signa 1 amplitude. The magnetic picture hooks are less effective than the bar magnets in Question 2 , because their internal array of flat magnets do not tend to produce fields that are as strong at a distance. The test was repeated with the tape enclosed in its plastic container and with the magnetic picture hook strapped to the container for 2 days. No observable signal loss occurred.

\section{d. Question 4}

Could someone attach the picture hook to the rack in an obscure place and destroy a number of tapes over a period of a month?

(1) This question has been answered by the previous comments. Time is no element in the destructive process; only the maximum magnetic field strength and proximity to the tape are important. The picture hook out of direct contact with the flanges on the reels of tape is ineffective as a signal erasing device. As a matter of fact, when a permanent magnet is fastened to a metal rack surface by magnetic attraction, its flelds tend to be "short circuited" or "shielded" by the metal and are even less effective than before at any distance from the magnet.

\section{e. Question 5}

Given a one-story buflding housing a tape storage area, could someone place a permanent magnet weighing $18 \mathrm{~kg}$ (40 1bs) on the roof and have any effect on the tapes?

(1) On the basis of the rule-of-thumb that was stated in section 3.1.(3) the field of a magnet will decrease to approximately

$$
\frac{1}{10} \times \frac{1}{10} \times \frac{1}{10}=\frac{1}{1000}
$$

of its field value that existed at $0.305 \mathrm{~m}$ ( $1 \mathrm{ft}$ ) from the pole faces if we move $3.05 \mathrm{~m}(10 \mathrm{ft})$ from the magnet. At the present time there are no permanent magnets available that can completely erase the information from a magnetic tape that is placed $0.305 \mathrm{~m}$ (1 ft) away from the magnet.

\section{f. Question 6}

Given a first floor installation separated from the street by a $6.1 \mathrm{~m}(20 \mathrm{ft}) \mathrm{sidewa} 1 \mathrm{k}$, with the tape racks $30.5 \mathrm{~m}$ (100 ft) from the 
curb, could someone place an electromagnet (of the type used in junk yards to load scrap) on its side in a van, connect the magnet to a series of automobile storage batteries in the van, drive up to the curb outside the computer room and, in say a minute, wipe out the entire installation's file and programs?

(1) This experiment was actually simulated at a local scrap metal (junk) yard on April 2, 1971. Four recorded tapes were placed into the fleld of a scrap lifting magnet at various distances: at $0.41 \mathrm{~m}(1.3 \mathrm{ft})$, at $1.52 \mathrm{~m}$ ( $5 \mathrm{ft})$, and at $3.05 \mathrm{~m}$ (10 ft). At $0.41 \mathrm{~m}(1.3 \mathrm{ft})$ a uniform signal loss of approximately $5 \%$ was observed. At $1.52 \mathrm{~m}(5 \mathrm{ft}$ ) and above no observable loss occurred. According to the crane operator, the magnet had a lifting capacity of approximately $363 \mathrm{~kg}(800 \mathrm{lbs})$ of scrap metal. However, the gap structure of the lifting magnet is such that there is little magnetic field strength extending outward from the magnet face. This type of a lifting magnet is effective primarily upon contact with the material and cannot perform at a distance as suggested.

(2) Now consider a non-lifting type of electromagnet: a magnetic field forms around any wire through which electric current flows. This field can be made very powerful by shaping the wire into the form of a spring-like coil or "solenoid" and increasing the current flow. However, increased current flow requires more power from the electrical supply as well as cooling systems for the coils. Coils that are specifically designed for producing very strong magnetic fields that are in the range from approximately 8 to 40 million $\mathrm{A} / \mathrm{m}$ ( 100,000 to 500,000 oersted) are not designed to produce fields at a long distance. They are always constructed to produce concentrated magnetic fields in the center region of the coils and are used to perform basic scientific experiments on materials that are placed into the most powerful regions of the coil field. For example, one known't high intensity water-cooled magnet coll which has approximately a $12 \mathrm{million} \mathrm{A} / \mathrm{m}(150,000$ oersted) field near its center drops to less than approximately $80,000 \mathrm{~A} / \mathrm{m}$ (1000 oersted) within $0.305 \mathrm{~m} \mathrm{(} 1 \mathrm{ft}$ ) of the coil center. This magnet requires a power supply that is capable of supplying at least 3 million watts of electrical power to the coil. A magnet system such as this is impossible to transport in any ordinary vehicle. Less magnet power is required to produce a strong magnetic field if the coll is wound around an iron "core". However, an iron core limits the maximum electromagnetic field strength to a value that is well below the maximum field that can be produced by a coil with an "air" core alone. The most powerful distant field can be produced by an electromagnet coil with a straight line shape while a magnet that is bent into the shape of a "U" or a "horseshoe" develops more intense "local" or close-up fields but weaker distant fields.

*"Bitter" type magnet at the Naval Research Laboratory High Magnetic Field facility, Washington, D.C. 
A low temperature "cryogenic" magnet operating in a "pulsed field" mode is an exotic and more profitable way to develop extremely high field intensities with truck portable magnets [3]. Experiments have not yet been performed to determine their effective erasing range. However, it may be stated that within the present state-ofthe-art it is not possible to produce a distant field with a mobile electromagnet in any known form that is capable of erasing the recorded signal from a magnetic tape at $30.5 \mathrm{~m}$ (100 ft) from the source.

\section{g. Question 7}

Is there any way to shield the information on a magnetic tape from an outside magnetic field produced by a magnet or a motor?

It has been shown that recorded information on a magnetic tape can be shielded from the effects of a magnetic field by keeping the tapes at a distance from a source such as a permanent magnet or motor. It is also possible to shield the tape further by placing it either into an individual container or into a vault whose surfaces are made of ferromagnetic "shielding" materia1 [4]. These materials are good conductors of both electricity and magnetic "flux" and will short-circuit the path of the magnetic field. That is, most of the magnetic field energy is absorbed in the shielding material and very little passes through it into the air on the opposite side. The shield is usually fabricated from some ferrous or ferrite material in a number of different physical forms such as sheets, rolls and coatings of various thicknesses. Hypernick, Permalloy, Mu-meta1, Netic and Co-netic are examples of shielding materials for magnetic fields. A multi-layer shielding structure can be devised by using the proper combinations of materials and air space. For example, Netic shielding has been designed for reducing the strength of very powerful magnetic fields while Co-Netic is designed to absorb weaker magnetic fields. Therefore, a layer of Netic can be placed close to the outside of the tape enclosure in order to absorb most of the incoming magnetic field. This can be followed by an air space, and then a layer of Co-Netic close to the interior wall of the enclosure will absorb the remaining field.

Figure 7 in section 4.3 shows the effect of a large permanent magnet on a recorded reel of magnetic tape. When the magnet is placed $38 \mathrm{~mm}$ ( $1.5 \mathrm{in}$ ) from the tape surface a $15 \%$ signa 1 los $\mathrm{s}$ is sustained on the beginning footage. When a piece of $1.3 \mathrm{~mm}(0.050 .1 \mathrm{n})$ thick Mu-metal shielding is then placed between the tape reel and the magnet there is no observable signal loss as shown in figure 8 in section 4.3 .

A potential source of unwanted magnetic fields such as a large motor, generator or transformer that is near the tape installation should also be enclosed in shielding materials. The shield layer or layers should be at least $6.4 \mathrm{~mm}(0.25 \mathrm{in})$ or more away from the 
device and should surround it completely. Whenever possible, the initial placement of the tape repository should avoid sources of unwanted fields.

There are several organizations whose primary function is the production, design and engineering of shielded environments. It is a worthwhlle idea to consider using their services.

\section{h. Question 8}

Are there magnets available that are much more powerful than the little office bar or picture hook magnets but that are still easy to conceal and to carry about?

Yes, there are. The tests that were performed with a concealable magnet which weighed approximately $0.80 \mathrm{~kg}(1.75 \mathrm{lbs})$ and had a maximum center field strength of approximately $56,000 \mathrm{~A} / \mathrm{m}$ ( 700 oersteds) indicated that they can be extremely effective even when they contact the outer edges of the tape reel as it is stored in a vertical position. Figure 5 in section 4.3 shows that the signal on the first $210 \mathrm{~m}$ (700 ft) of a recorded tape was badly damaged. The broad dark trace on the left side of the chart represents a significant loss of signal strength. The dark trace becomes progressively thinner as the signal loss decreases with distance into the tape reel and ends up at its normal undamaged signal level.

The results of a number of tests that were performed with this magnet are described in Section 4.3.

\section{DESCRIPTION OF EXPERTMENTS}

\subsection{Experimenta1 Procedures}

In each of the following experiments computer tapes were first recorded with continuous pulse trains and were then subjected to the magnetic fields from different permanent magnets at varying distances. The resulting peak signal levels were then measured in the NBS Magnetic Media Measurement Laboratory with the NBS reference tape signal amplitude measurement system [5]. The signal peak outputs from various read head tracks were read from the tape on an IBM 2401-VI tape transport at a speed of 2.86 meters per second ( 112.5 inches per second) and were recorded by a strip chart recorder as shown in figure 2. In some cases the chart speeds were varied from slow ( $1 \mathrm{~mm} / \mathrm{second}$ ) to fast $(125 \mathrm{~mm} / \mathrm{second}$ ) in order to display fine signal deta11. For example, in figure 2 and 3 each drop in signal level coincides with a single rotation of the tape reel. This drop occurs at the positions of the tape surface closest to the point at which the magnet touched the reel flange. At the slow chart speeds of $1 \mathrm{~mm} / \mathrm{sec}$ ond all of the drops in signa 1 level merge into a solid trace. At this slow speed each vertical 


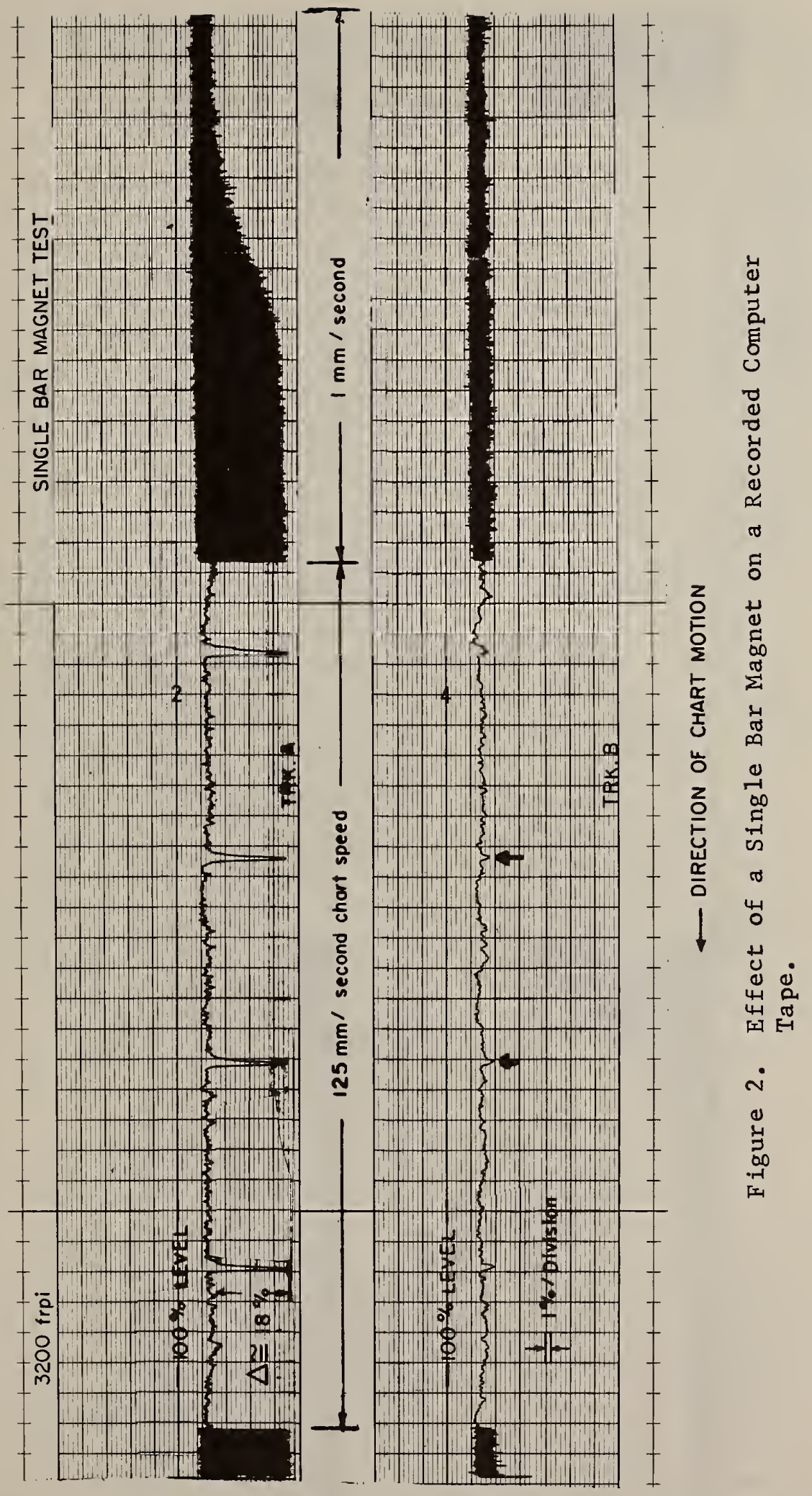




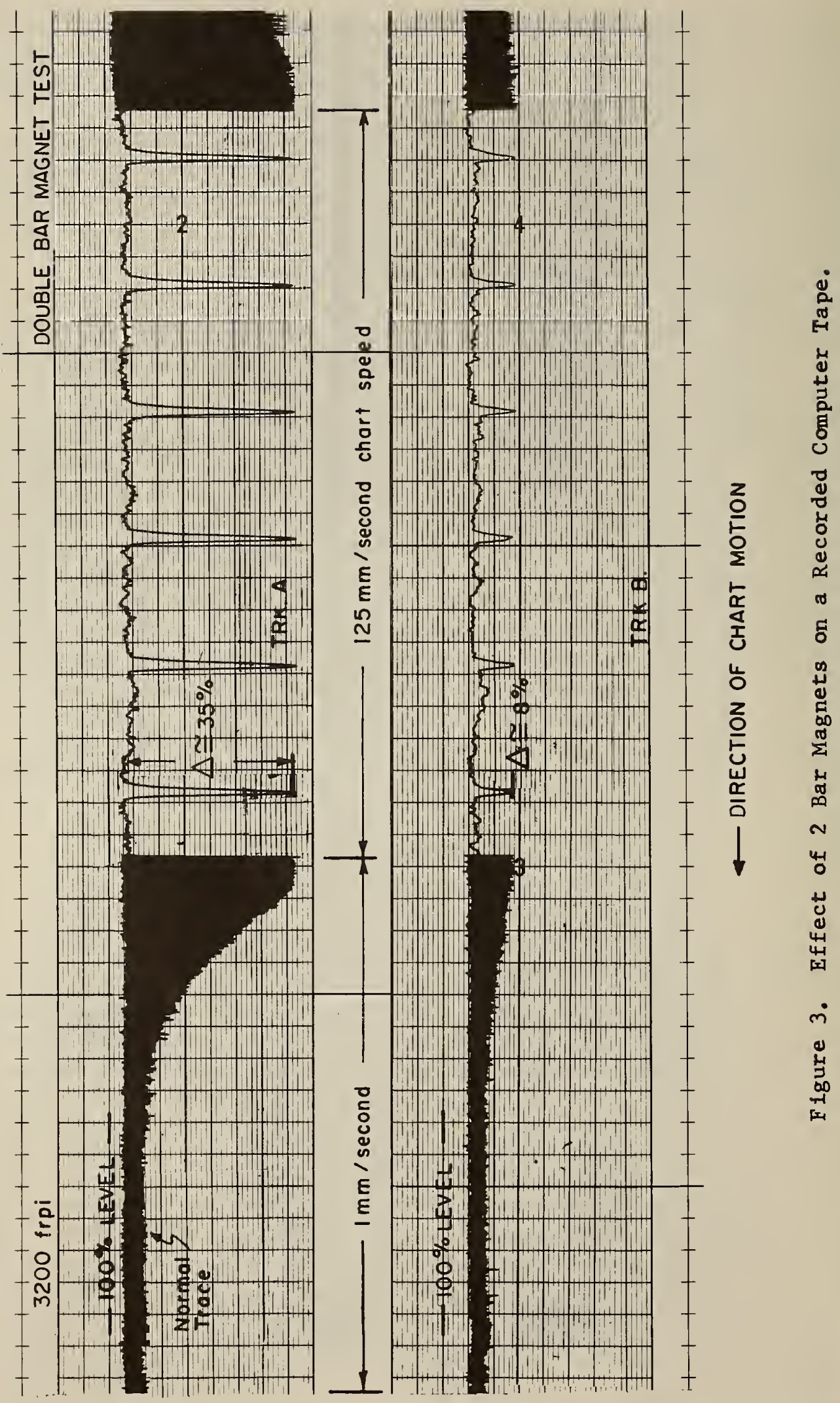


chart line represents a passage of approximately $14.3 \mathrm{~m}$ (47 ft) of tape. Each horizontal line represents a $1 \%$ variation in signal level.

\subsection{Sma11 Bar Magnet Experiments}

a. Experiments were performed to determine whether the signal levels of stored data on a reel of magnetic tape can be altered or destroyed with typical office type $25 \mathrm{~mm} \times 3.2 \mathrm{~mm} \times 3.2 \mathrm{~mm}$ ( 1 in $x 0.13$ in $x 0.13$ in) Alnico bar magnets and $51 \mathrm{~mm} \times 102 \mathrm{~mm}$ (2 in $x 4 \mathrm{in}$ ) picture hooks. The field strengths of the bar magnets and hooks were measured with a Hall probe-gaussmeter combination. The bar magnets had maximum field intensities of approximately 44,000 to $52,000 \mathrm{~A} / \mathrm{m}$ (550 to 650 oersteds) and the picture hooks had maximum intensities of approximately 36,000 to $40,000 \mathrm{~A} / \mathrm{m}$ (450 to 500 oersteds). These fields are greater than the typical computer tape coercivities which range from approximately 20,000 to 21,000 $\mathrm{A} / \mathrm{m}$ (250 to 265 oersteds). Therefore, it is only the spacing loss produced by the reel flange thickness plus the spacing of the data bit position from the inside flange surface that prevent even worse obliteration of the recorded signals.

Figure 2 shows the peak signa 1 levels on tracks A (Track No.2) and track B (Track No.5) of a computer tape which has been recorded with a $180 \mathrm{kHz}$ pulse train*. This is a $3200 \mathrm{frpi}$ (NRZI) signal. The end of a single bar magnet had been pressed against the side of the plastic reel flange on the track A side of the tape ree 1 immediately after recording. The center of track A was spaced approximately $4.2 \mathrm{~mm}$ (0.16 in) from the pole of the magnet as it contacted the flange. Track $B$ is near the centerline of the tape and is at most $4.3 \mathrm{~mm}(0.17 \mathrm{in})$ from the center of track A. The signal levels shown in figure 2 were measured during the first "read-afterwrite" pass。 Track A displays a peak signal leve1 drop of $18 \%$ and track $B$ displays a $2 \%$ drop. The average overa 11 tape signa 1 peak leve 1 had decreased by $3 \%$ from the first "read-while-write" pass (not shown) due to the normal demagnetization effects not related to the bar magnets.

b. Figure 3 shows the effects on the same recorded signal that are now produced by the contact of 2 bar magnets whose magnetic fields have been forced outward by placing their "1ike" poles together. This effectively increases the volume of the magnet. The peak signa 1 in track $A$ has sustained a $35 \%$ decrease in signal amplitude, track $B$ an $8 \%$ decrease and now even track $C$ (not shown) whose center is approximately $8.2 \mathrm{~mm}$ ( $0.32 \mathrm{in}$ ) away from the center of track $A$ has sustained a $3 \%$ loss in signal amplitude. Tests with the NBS drop-out measuring device did not detect signal level losses below these levels.

*

* The tracks are numbered in accordance with USA Standard Recorded Magnetic Tape for Information Interchange (800 CPI, NRZI)-USASI X3.22-1967. 
Additional tests that were run with aluminum flange reels displaye equivalent effects since aluminum is not ferromagnetic and does not shield the tape. These signal losses are dangerously close to producing information losses in practical systems where a dropmout is typically a $50 \%$ decrease from some nominal system level.

\subsection{Large Magnet Experiments and Tests}

a. Serious attempts at the large scale destruction of tape libraries would probably be made with powerful magnets that could be concealed in the pocket or purse. Also, since magnetic tape reels are normally stored next to each other in a vertical position, the magnet would tend to be pressed in the vicinity of the outer flange edges rather than against the inaccessible sides of the ree 1 flanges. The following series of tests were performed with the concealable magnet that was referred to in Question 8. The plot of the magnetic field strength in the region surrounding the magnet poles is shown in figure 4 as the field lines enter the tape pack. Only one side of the field is shown; the mirror image of that field is on the other side of the centerline. There are magnetic field density regions close to the pole face edges that are as high as $0.25 \mathrm{~T}$ (2500 gauss). These do not reach the tape and are not shown in the figure. The field strength lines are shown in terms of both $1000 \mathrm{X} \mathrm{A} / \mathrm{m}$ and oersteds as they exist within the tape ree 1 upon direct magnet-to-reel contact. The field strength at each plotted position was found to be the same when the space between magnet and measuring probe was filled either with air or with layers of magnetic tape.

b. The $730 \mathrm{~m}$ (2400 ft) long tapes used in the following tests were pre-recorded at 3200 frpi bit density. In each case $13 \mathrm{~mm}$ $(0.50 \mathrm{in})$ must be added in order to determine the magnet-to-tape distance since the outermost layer of tape begins this far in from the outer edge of the reel flange:

(1) Test 1: Figure 5. The magnet was contacted edge-on against a recorded ree1 of tape that was protected only by a wraparound container. The erasing effectiveness of the magnetic field as a function of distance into the tape can be seen by the gradual variation in the tape peak signal level. The heavy dark area represents the drop in signal level to a value more than $40 \%$ below the nominal system leve1. Note that the information has been badly damaged on approximately the first $210 \mathrm{~m}$ (700 ft) of tape. Figure 6 shows a plot of "\% Signal Decrease" versus "Distance Into Reel" obtained from figure 5. For example, at a distance of approximately $46 \mathrm{~mm}(1.8 \mathrm{in})$ in from the outside edge of the reel flange (the position of the magnet poles) towards the center of the tape reel the signal has been decreased by $5.5 \%$. This point is approximately 490 (1600 ft) in from the beginning of the tape. The erasing field strength and the signal loss at each distance along the tape can 


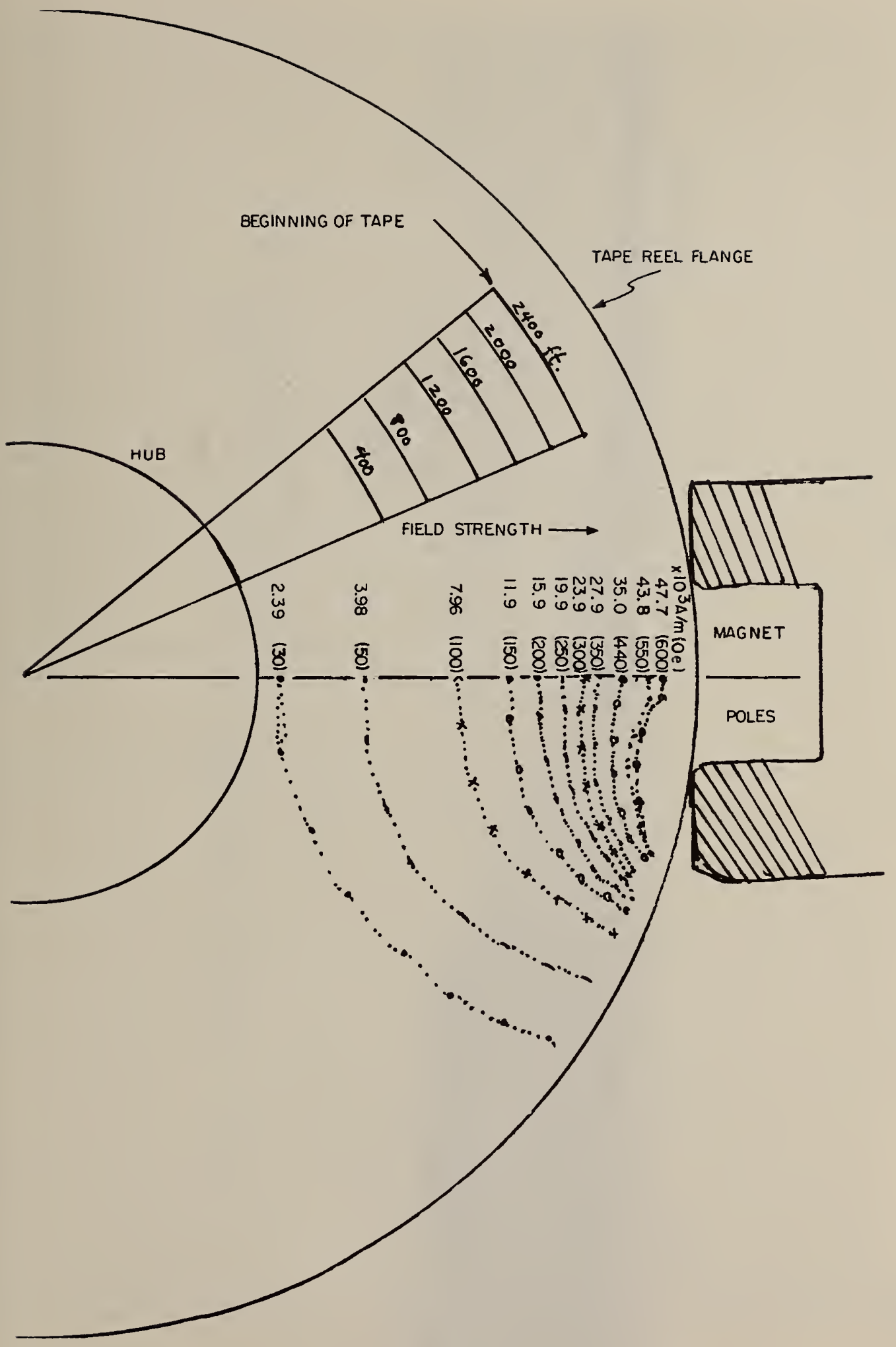

Figure 4. Magnetic Field Produced by the Large Test Magnet. 


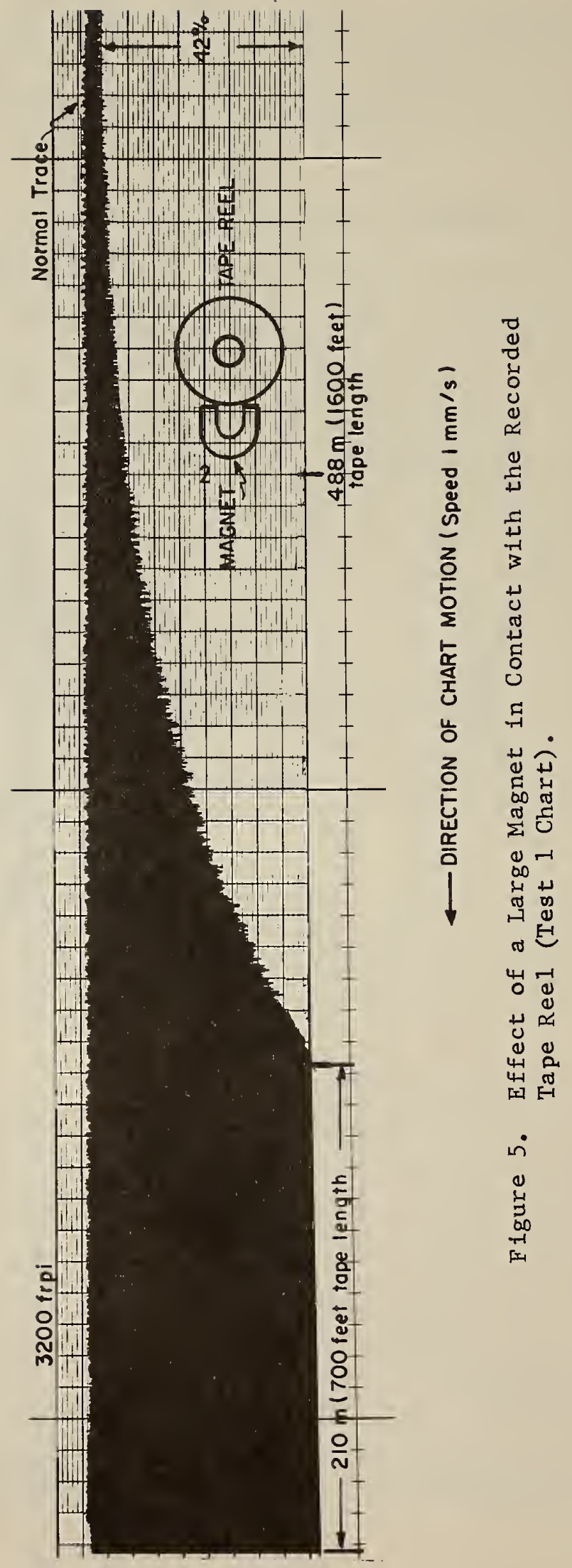




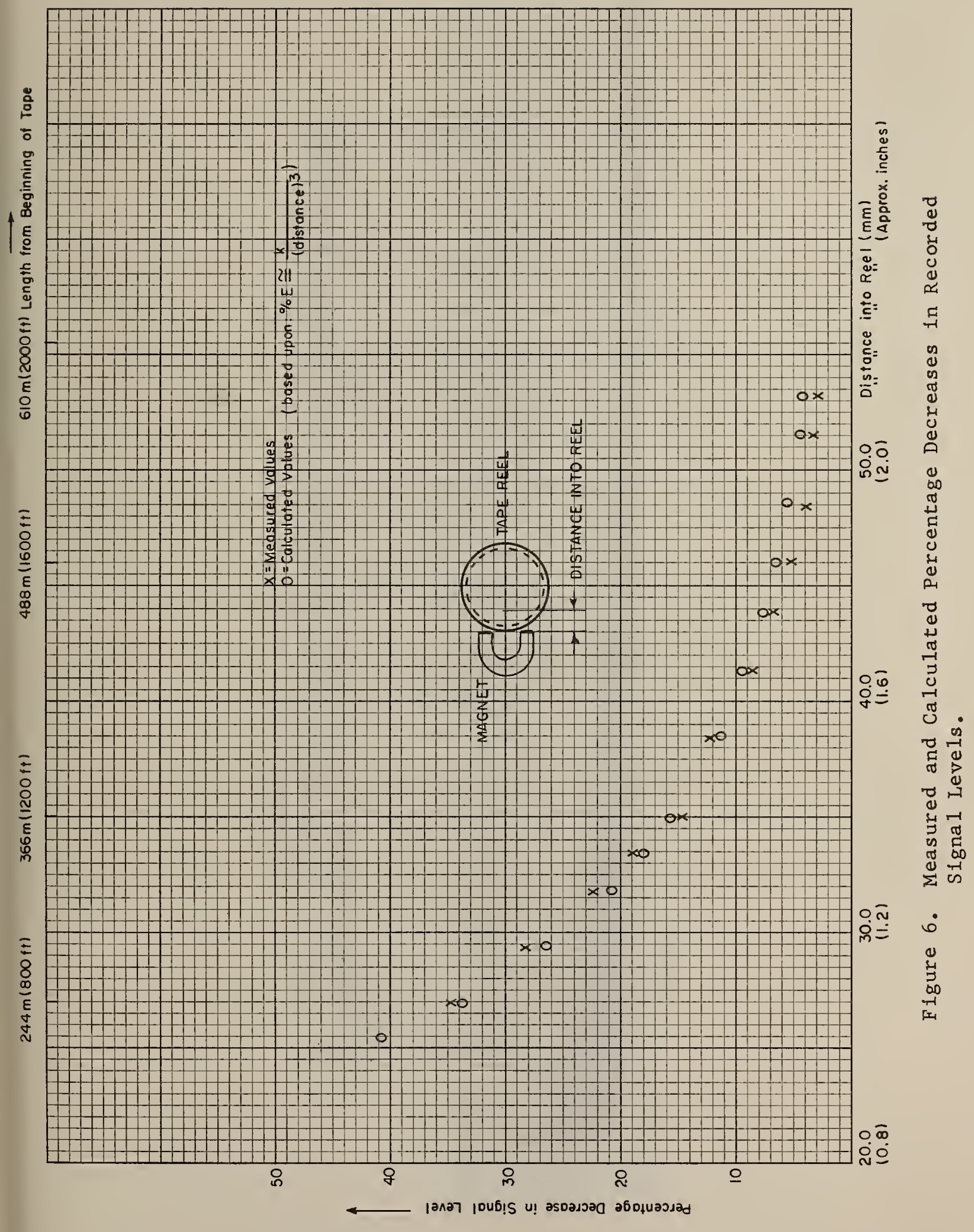




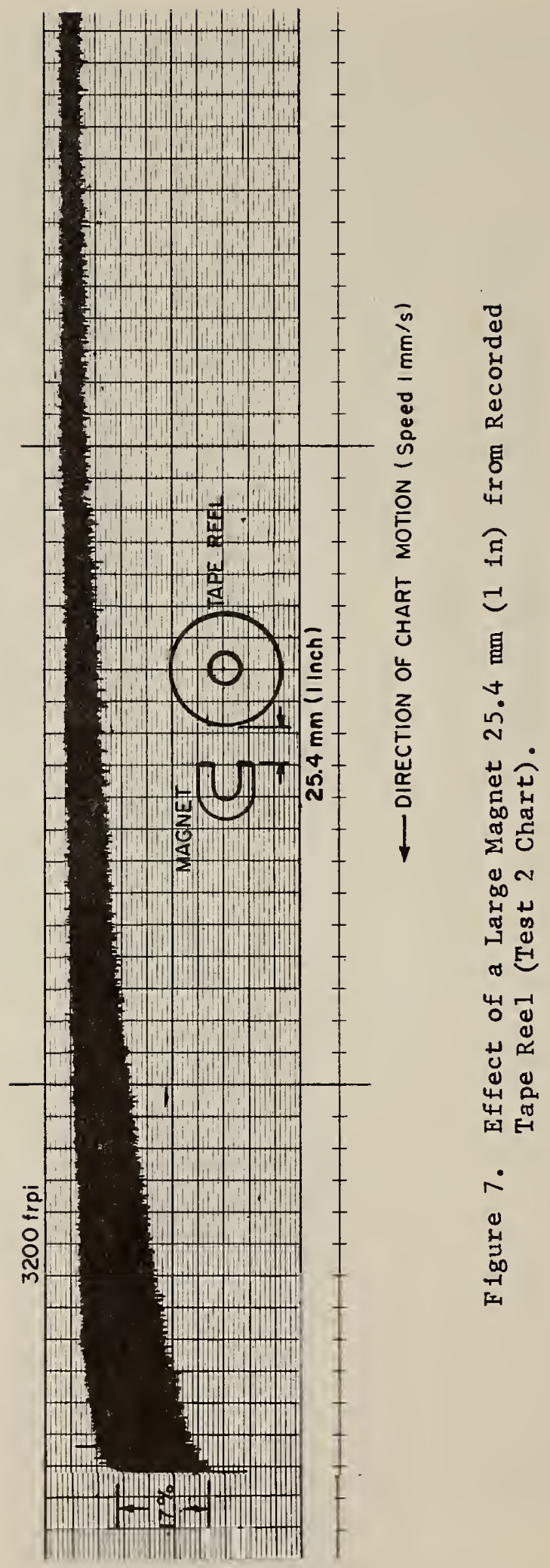




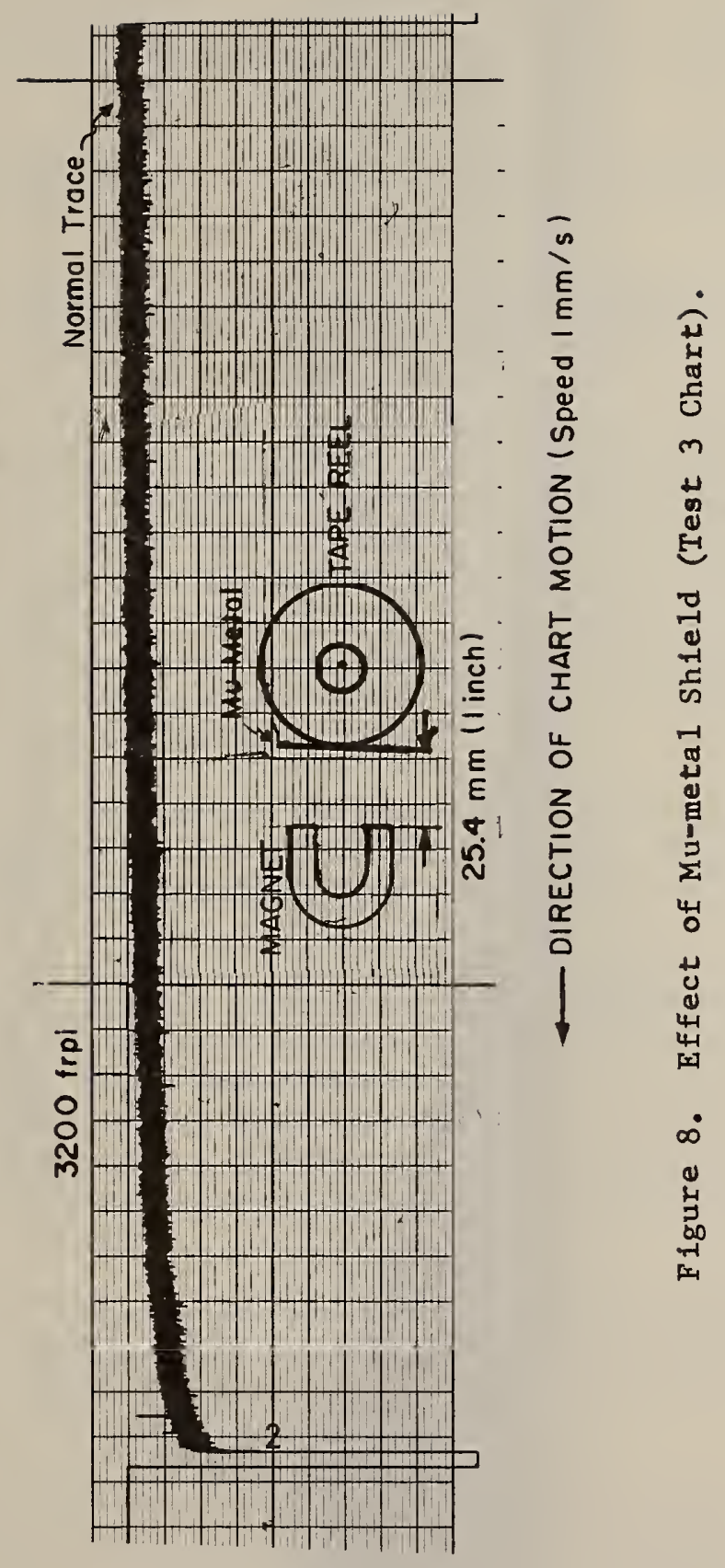




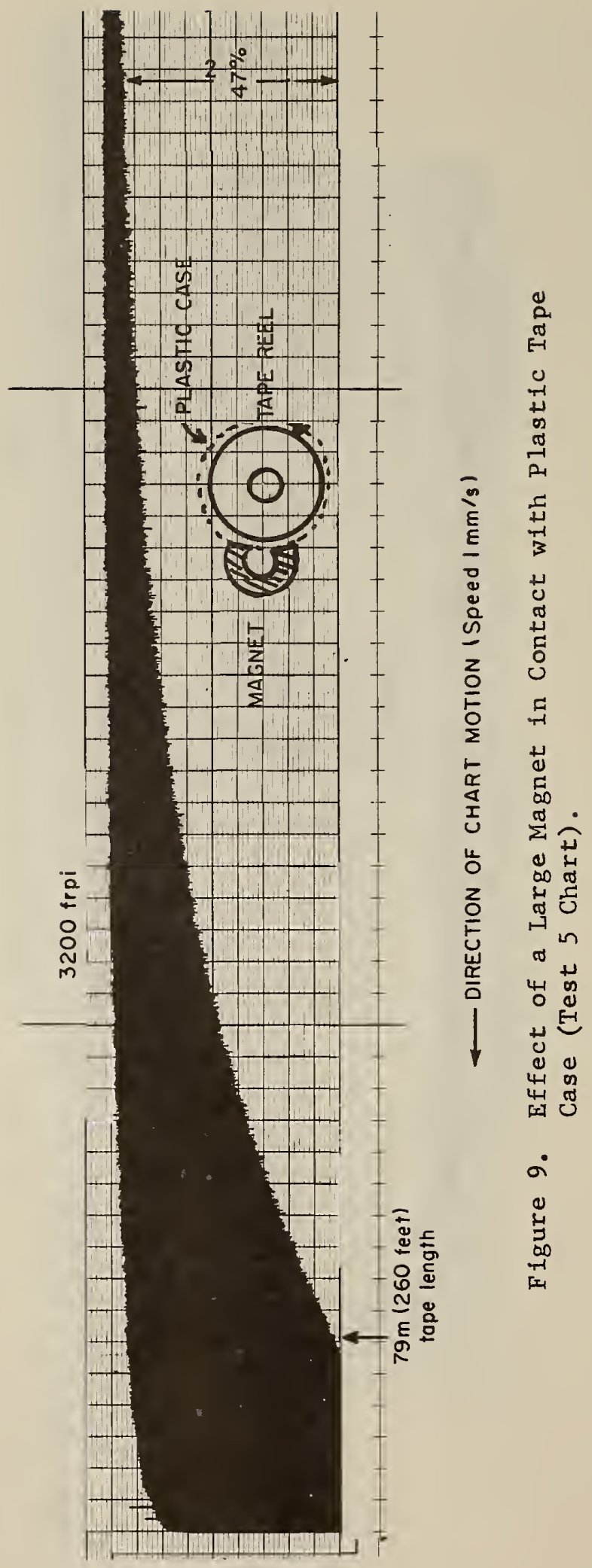


be derived from figures 4 and 6 . It is of interest to note that the curve that is fitted to the measured data in figure 6 is proportional to $\frac{1}{(\text { distance })^{3}}$. This indicates that the signal

strength on this tape decreased at an inverse cube rate in the same manner as a distant magnetic field.

The following tests 2 through 4 were each performed with a wrap-around container:

(2) Test 2: Figure 7. The magnet was moved approximately $25 \mathrm{~mm}$ ( $1 \mathrm{in}$ ) away from the reel edge. The maximum signal level loss on the beginning tape footage was approximately $17 \%$.

(3) Test 3: Figure 8. The magnet was moved back approximately $25 \mathrm{~mm}$ ( $1 \mathrm{in}$ ) from the reel edge and a piece of Mu-metal $1.3 \mathrm{~mm}$ ( 0.050 in) thick was placed between the tape and the magnet in contact with the edge of the reel. There was no measurable signal loss. However, when the magnet was brought into direct contact with the Mu-metal (that is, zero air space) the first $61 \mathrm{~m}$ (200 ft) of recorded tape signal was badly damaged. This indicated that the Mumetal was saturated and its "permeability" was greatly decreased by the strong magnetic field.

(4) Test 4: The magnet was moved back $51 \mathrm{~mm}$ (2 in) from the reel edge. There was no observable signal loss. This shows the value of distance as a shield. The trace is the same as figure 8 .

(5) Test 5: Figure 9. The reel of tape was placed into a typical full-sized plastic container. This produces an additional $13 \mathrm{~mm}(0.5 \mathrm{in})$ end air space between the magnet and the reel. The signal was reduced by at most $50 \%$ at the beginning of the tape. The recovery of the signal level to above the $45 \%$ loss level occurred at the $79 \mathrm{~m}(260 \mathrm{ft})$ mark. In the case of the direct magnet-to-reel contact of Test 1 this recovery leve 1 was not reached until close to the $210 \mathrm{~m}$ (700 ft) mark.

(6) Test 6: Figure 10. The reel was pre-recorded at 200 frpi and placed into a wrap-around container. The general effect was similar to that in Test 1 except for the erratic trace which. could have been caused by the angle of the magnet.

A11 of these tests were performed with the magnet positioned as shown in figure 5. The magnet is in the "easy" magnetizing position and will produce the maximum signal damage at a given distance. If the magnet is rotated 90 degrees into the "transverse" position its erasure effect is reduced from a $45 \%$ or greater signal loss over the first $210 \mathrm{~m}(700 \mathrm{ft})$ of tape to the same loss on $1 \mathrm{y}$ over the first $76 \mathrm{~m}(250 \mathrm{ft})$. 


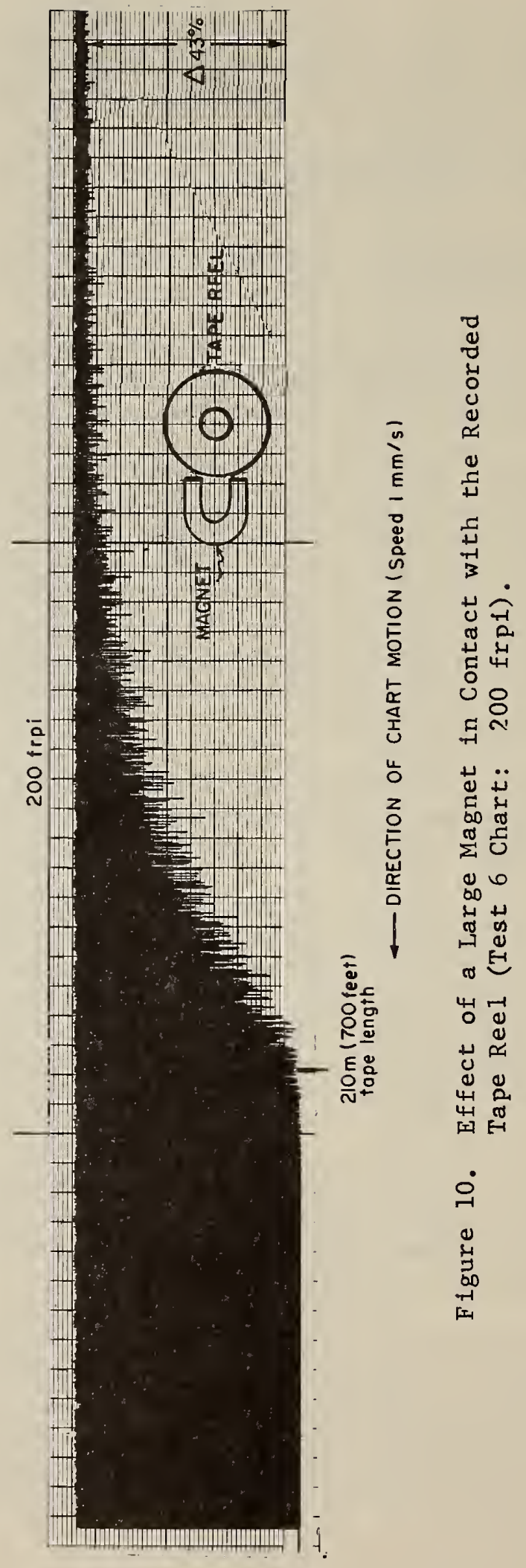


Tests such as these suggest that it may be of benefit to use the standard $267 \mathrm{~mm}$ (10.5 in) diameter computer tape reel with a reduced amount of tape footage. This would move the beginning of the recorded tape away from the outside reel edge. Alternately, it may be possible to use standard $730 \mathrm{~m}$ (2400 ft) long computer tapes with the important information recorded nearest to the inside hub. However, these precautions will be nullified if the magnet has access to the side of the tape reel flange. The field plot in figure 4 suggests that side flange contact with this $0.80 \mathrm{~kg}(1.75 \mathrm{lb})$ magnet would be devastating.

\section{ADDITIONAL TEST RESULTS AND COMMENTS}

a. A11 of the tests that were performed were evaluated in terms of the signal peak level changes that were caused by permanent magnet fields. A test was also performed to determine whether any detrimental waveshape distortions occurred due to these dc fields. In order to do this experiment, a cassette tape was recorded at 1600 frpi and then subjected to a double bar magnet contact at its side flange. The tape was then read back at $127 \mathrm{~mm} / \mathrm{sec}$ ond ( 5 inches/second). This is sufficiently slow so that the individually reproduced waveshapes could be stored and displayed on the tube of a storage oscilloscope at both the nominal $100 \%$ level and the damaged level. The signals with the reduced levels appeared once per revolution (see section 4.1 ) and were approximately $44 \%$ below the nominal level. However, the signal waveshapes were relatively undistorted and their recovery as information would not be affected by distortion phenomena. Only the reduction in signal amplitude appears likely to be the cause of information losses, particularly in an "amplitude" detection type of computer tape reproduce system.

b. There were no erasure tests run with a slowly varying ac magnetic field; however, the information derived from the permanent magnet tests is useful for both cases. The "peak rule" for ac magnetic fields holds. That is, the recorded signal on the tape will be affected mostly by the maximum or peak value that the ac field achieves. Once the tape record is subjected to that maximum value it will suffer an irreversible loss of signal. As the field goes towards zero value it is similar to the process of withdrawing the permanent magnet. However, since the ac field then reverses its direction at a $60 \mathrm{~Hz}$ rate it will eventually tend to have a more destructive and randomizing effect on the signal content. It is as though the permanent magnet poles were turned back and forth through $180^{\circ}$ at this rate. However, the peak value of the ac field requires approximately the same intensity value as the dc field if it is to produce complete signal destruction.

c. Although the pertinent tests were not performed at NBS the following information of interest has been gathered: 
(1) Microwave electromagnetic fields are ineffective for magnetic tape signal destruction unless the tape is extremely close to the antenna. This is because the magnetic component of the field loses its strength very rapidly with distance from the antenna. In one series of tests groups of recorded tapes were placed in various positions at a distance of approximately $460 \mathrm{~m}(1500 \mathrm{ft})$ from a 5 million watt, pulsed radar antenna. They remained there for 27 days and were then subjected to a number of rigorous tests including signal-to-noise, print-through and signal amplitude. Result: No detrimental effects were observed [6].

(2) Nuclear radiation is ineffective as a magnetic tape signal destroying force except, of course, where physical destruction of the tape backing or oxide can occur. The electromagnetic field associated with a nuclear burst is not sufficiently strong to produce signal erasure, although its irradiation effects may cause damage to the oxides or backing [7].

(3) Initial information to date indicates that the magnetic field emanating from the airport metal and gun detector systems are too weak to cause destruction of the signal on a recorded computer tape. For example, one such system produces a field intensity of less than $80 \mathrm{~A} / \mathrm{m}$ ( 1 oersted) [8]. It is important that the designers of these detection systems be cognizant of the difficulties which may accrue if they design units with more powerful searching fields. Otherwise it may be necessary to develop alternate handling and trafficking methods for recorded magnetic tapes.

(4) Available information on the effects of lightning strokes on recorded magnetic data indicates that the tape must be within $3.05 \mathrm{~m}(10 \mathrm{ft})$ of the center of the bolt in order to sustain observable damage and within $0.91 \mathrm{~m}$ ( $3 \mathrm{ft}$ ) before severe erasure occurs. The current at the center of the bolt is approximately $10^{5}$ amperes [9].

(5) Excessive temperatures can cause signal loss especially as the Curie temperature of the iron oxide in the tape is approached. In fact, there is a method of recording on magnetic tape known as "thermoremanent" or "Curie Point" recording in which the oxide is heated to approximately $675^{\circ} \mathrm{C}$. Near this temperature a very small magnetic field can either magnetize or demagnetize a tape [1]. However, the base material of the magnetic tape will undergo physical damage and deformation at much lower temperatures. Figure 11 shows the effects of temperature and humidity on various base materials. This figure has been reproduced from the Ampex "Trends" Application Engineering Bulletin No. 2., July 1963.

d. Since the characteristics of the magnetic media surfaces as well as the recording mode and the record/reproduce system philosophy will all affect the extent of the damage that a given device can accomplish it is felt that a study of different methods for recovering information from damaged tapes and for designing 
system philosophies that minimize information loss would be highly valuable.

(1) For example, the surface of the magnetic recording media usually consists of either smal1 "ferromagnetic" particles that are held in a paint-like "binder" or of a thin layer or film of ferromagnetic material which has been "plated" onto the surface. The RAMAC and most random access disks as well as a11 computer tapes are examples of media having "particulate" magnetic surfaces. FASTRAND drums and video files are examples of the film type of magnetic recording surfaces. In either case it is possible to design the surface of the medium to be more or less resistant to erasure by unwanted fields. For example, a resistant medium can be fabricated with a very thin, very high coercivity magnetic surface. There is, however, considerable interaction between coercivity and temperature for certain types of films [10]. Therefore, the surface design must take into consideration the characteristics of the system and the environment in which the media will be used.

(2) Most of the methods that are used for reproducing the data from computer tapes fall into the categories of either "amplitude" or "peak" detection [11]. The amplitude detection process senses the presence of a pulse for a binary " 1 " and the absence of a pulse for a binary " 0 " information. In order to suppress the effects of system noise the amplitude detection method usually requires that the incoming signal shall achieve some threshold level. If the signal that is reproduced from a tape does not reach the required level it is lost as information. In the peak detection process signal cross-over points control the information output. Since initial test results indicate that the field of a permanent magnet primarily causes the loss of signal amplitude, it is felt that a peak detection method is more resistant to information loss on damaged computer tapes.

(3) The resistance of magnetic media to information loss is also influenced by the encoding scheme that is used. For example, phase recording withstands the effects of unwanted magnetic fields better than amplitude recording since it is easier and less expensive to recover the information on this type of encoding scheme. Techniques exist for recovery of signal from magnetic media onto which significant levels of noise have been introduced. A finding in this regard is that NRZI recordings are less susceptible to "damage" than many other recording techniques.

The contributions made by Dr. Ruth M. Davis to sections 2 and $5 d$ are gratefully acknowledged. 


\section{REFERENCES}

[1] Mee, C. D., The Physics of Magnetic Recording, Chapters 3 and 4, p. 80 and p. 134, North Holland Publishing Co., Amsterdam, (1964).

[2] Becker, J. J., Permanent magnets, Scientific American, 223, No. $6,92-100$, (1970).

[3] Parkinson, D. H., Mulha11, B. E., The Generation of High Magnetic Fields, Plenum Press, New York (1967).

[4] Robinson, J. G., Fundamentals of EMI shielding, ElectroTechnology 77, No. 6, 36-39, (1966).

[5] Geller, S. B., Calibration of NBS secondary standard magnetic tapes (Computer Amplitude Reference) SRM 3200 using the reference tape amplitude measurement "Process A" Model II, NBS Special Publication 260-29, (1971).

[6] Byrd, V., Effects of radar signals on recorded magnetic tapes, NASA Technical Note, Private Communication, (1967).

[7] Computer Talk, The handling and storage of computer tape, Magnetic Products Division 3M, 1 , No. 1, (1968)。

[8] Monahan, J. S., Airline meta 1 detector inspections, Applications Bulletin No. 4, Memorex Corpo, (1971).

[9] Pear, C. B., Magnetic Recording in Science and Industry, Chapter 3, 106, Reinhold Publishing Corpo, New York, (1967)。

[10] Lazzari, NoP. et al, Experimental studies used in contact recording on chromium cobalt films, IEEE Transactions on Magnetics, 5, No. 4, 955-959, (1960).

[11] Bycer, B. B., Digital Magnetic Tape Recording: Principles and Computer Applications, Chapter 5, 110-118, Hayden Book Co., N.Y., (1965).

[12] ASTM Metric Practice Guide, Handbook 102, U.S. Department of Commerce, National Bureau of Standards, (1967). 
The conversion factors which were used to relate the "customary" system of units to the new International System of Units (SI) are as follows:
(a) 1 foot converts to 0.3048 meters
(b) 1 gauss converts to 0.0001 teslas
(c) 1 inch converts to 25.4 millimeters
(d) 1 oersted converts to 79.57747 amperes per meter
(e) 1 pound converts to 0.4535924 kilograms
(f) 1 pound (force) converts to 4.448 newtons

Reference [12] was used as a guide for handling the numerical data in this report.

The expression magnet "power" has been used in section 3.1.a. only as a descriptive term and is not technically meaningful. The ability of a magnet to exert a force on a responsive material is a function of the intensity or strength of its external magnetic field. 


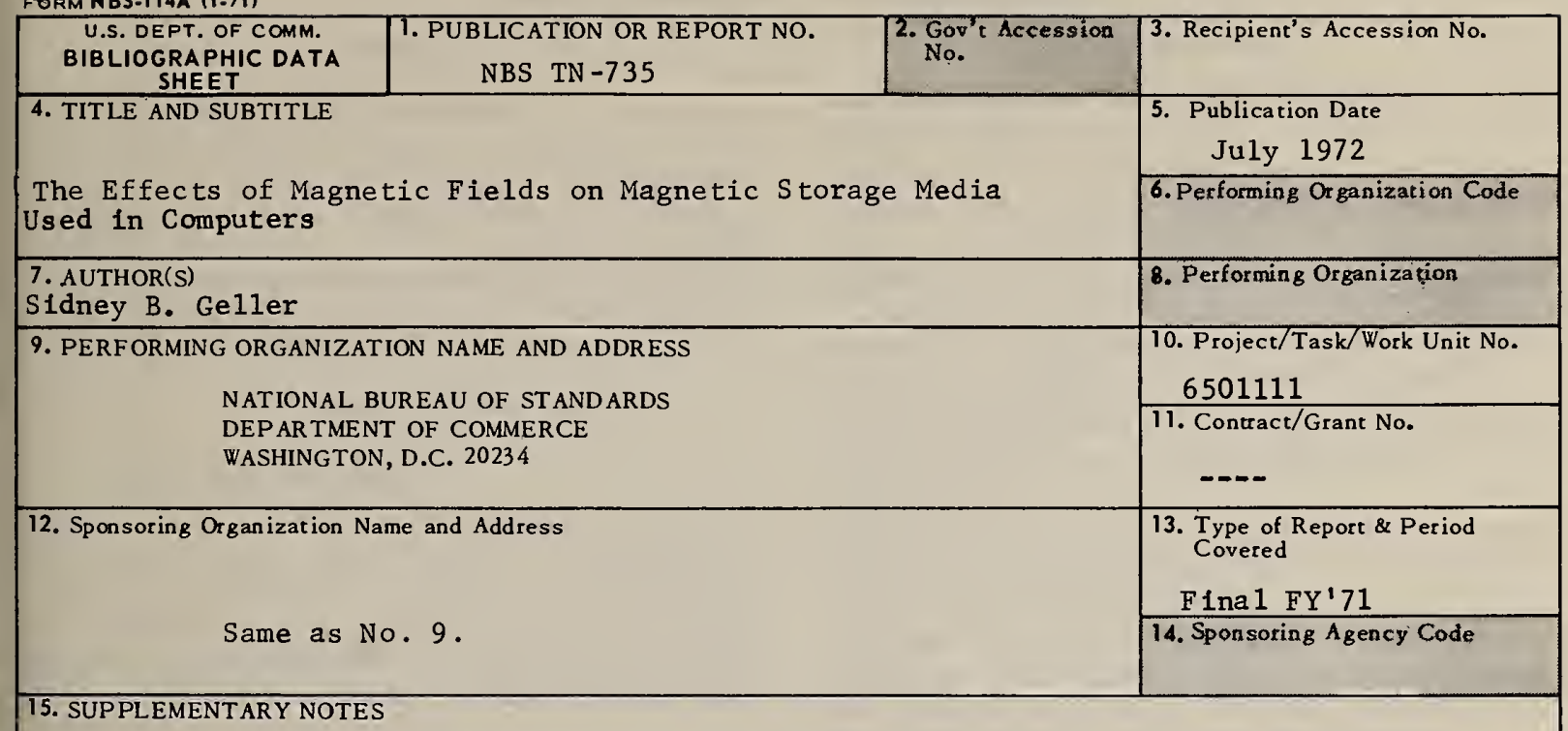

\section{SUPPLEMENTARY NOTES}

16. ABSTRACT (A 200-word or less factual summary of most significant information. If document includes a significant bibliography or literature survey, mention it here.)

. Experiments have been performed with different types of magnets to determine their effects on the information stored on magnetic storage media. The test results that were obtained with recorded computer tapes are discussed and guidelines are suggested to computer installation managers for protecting their recorded tapes, disks and drums against unwarranted erasure by magnetic fields. The effects of other forms of energy on recorded magnetic media are briefly considered.

17. KEY WORDS (Alphabetical order, separated by semicolons) Erasure, magnetic media; erasure, permanent magnet; erasure, shielding against; erasure, signal loss due to; magnet flelds, erasure with; magnetic media, computer; magnetic media, Information damage;

\begin{tabular}{|l|l|l|}
\hline 18. AVAILABILITY STATEMENT permanent magnets; permanent & 19. SECURITY CLASS & 21. NO. OF PAGES
\end{tabular}

DX UNLIMITE. $\quad$ magnet, er

FOR OFFICIAL DISTRIBUTION. DO NOT RELEASE TO NTIS.

\begin{tabular}{|c|c|}
\hline $\begin{array}{l}\text { 19. SECURITY CLASS } \\
\text { (THIS REPORT) } \\
\text { UNCL ASSIF IED }\end{array}$ & $\begin{array}{l}\text { 21. NO. OF PAGES } \\
35\end{array}$ \\
\hline $\begin{array}{l}\text { 20. SE CURITY CLASS } \\
\text { (THIS PAGE) } \\
\text { UNCL ASSIFIED }\end{array}$ & $\begin{array}{l}\text { 22. Price } \\
40 \phi\end{array}$ \\
\hline
\end{tabular}





\section{NBS TECHNICAL PUBLICATIONS}

PERIODICALS

JOURNAL OF RESEARCH reports National Bureau of Standards research and development in physics, mathematics, and chemistry. Comprehensive scientific papers give complete details of the work, including laboratory data, experimental procedures, and theoretical and mathematical analyses. Illustrated with photographs, drawings, and charts. Includes listings of other NBS papers as issued.

Published in two sections, available separately:

\section{- Physics and Chemistry}

Papers of interest primarily to scientists working in these fields. This section covers a broad range of physical and chemical research, with major emphasis on standards of physical measurement, fundamental constants, and properties of matter. Issued six times a year. Annual subscription: Domestic, $\$ 9.50 ; \$ 2.25$ additional for foreign mailing.

\section{- Mathematical Sciences}

Studies and compilations designed mainly for the mathematician and theoretical physicist. Topics in mathematical statistics, theory of experiment design, numerical analysis, theoretical physics and chemistry, logical design and programming of computers and computer systems. Short numerical tables. Issued quarterly. Annual subscription: Domestic, \$5.00; $\$ 1.25$ additional for foreign mailing.

\section{TECHNICAL NEWS BULLETIN}

The best single source of information concerning the Bureau's measurement, research, developmental, cooperative, and publication activities, this monthly publication is designed for the industry-oriented individual whose daily work involves intimate contact with science and technology-for engineers, chemists, physicists, research managers, product-development managers, and company executives. Includes listing of all NBS papers as issued. Annual subscription: Domestic, $\$ 3.00 ; \$ 1.00$ additional for foreign mailing.

\section{Bibliographic Subscription Services}

The following current-awareness and literaturesurvey bibliographies are issued periodically by the Bureau: Cryogenic Data Center Current Awareness Service (weekly), Liquefied Natural Gas (quarterly), Superconducting Devices and Materials (quarterly), and Electromagnetic Metrology Current Awareness Service (monthly). Available only from NBS Boulder Laboratories. Ordering and cost information may be obtained from the Program Information Office, National Bureau of Standards, Boulder, Colorado 80302 .

\section{MOHPERIODICALS}

Applied Mathematics Series. Mathematical tables, manuals, and studies.

Building Science Series. Research results, test methods, and performance criteria of building materials, components, systems, and structures.

Handbooks. Recommended codes of engineering and industrial practice (including safety codes) developed in cooperation with interested industries, professional organizations, and regulatory bodies.

Special Publications. Proceedings of NBS conferences, bibliographies, annual reports, wall charts, pamphlets, etc.

Monographs. Major contributions to the technical literature on various subjects related to the Bureau's scientific and technical activities.

National Standard Reference Data Series. NSRDS provides quantitative data on the physical and chemical properties of materials, compiled from the world's literature and critically evaluated.

Product Standards. Provide requirements for sizes, types, quality, and methods for testing various industrial products. These standards are developed cooperatively with interested Government and industry groups and provide the basis for common understanding of product characteristics for both buyers and sellers. Their use is voluntary.

Technical Notes. This series consists of communications and reports (covering both other-agency and NBS-sponsored work) of limited or transitory interest.

Federal Information Processing Standards Publications. This series is the official publication within the Federal Government for information on standards adopted and promulgated under the Public Law 89-306, and Bureau of the Budget Circular A-86 entitled, Standardization of Data Elements and Codes in Data Systems.

Consumer Information Series. Practical information, based on NBS research and experience, covering areas of interest to the consumer. Easily understandable language and illustrations provide useful background knowledge for shopping in today's technological marketplace.

\section{CATALOGS OF HBS PUBLICATIONS}

NBS Special Publication 305, Publications of the NBS. 1966-1967. When ordering, include Catalog No. C13.10:305. Price $\$ 2.00 ; 50$ cents additional for foreign mailing.

NBS Special Publication 305, Supplement 1, Publications of the NBS, 1968-1969. When ordering, include Catalog No. C13.10:305/Suppl. 1. Price $\$ 4.50 ; \$ 1.25$ additional for foreign mailing.

NBS Special Publication 305, Supplement 2, Publications of the NBS, 1970. When ordering, include Catalog No. C13.10:305/Suppl. 2. Price $\$ 3.25$; 85 cents additional for foreign mailing.

Order NBS publications (except Bibliographic Subscription Services) from: Superintendent of Documents, Government Printing Office, Washington, D.C. 20402. 
U.S. DEPARTMENT OF COMMERCE

National Bureau of Standards

Washington, D.C. 20234

DFFICIAL BUSINESS

Penalty for Private Use, $\$ 300$
POSTAGE AND FEES PAID

U.S. DEPARTMENT OF COMMERCE 215 